\title{
PHOTOLUMINESCENCE AND EPR SPECTRUM OF ZnO:Mn NANOCRYSTALS
}

\author{
O. V. Kovalenko*, M. F. Bulaniy, V. Y. Vorovskiy, O. V. Khmelenko \\ Oles Honchar Dnipro National University, Dnipro, Ukraine \\ *e-mail: kovalenko.dnu@gmail.com
}

\begin{abstract}
Nanocrystals of $\mathrm{ZnO}$ :Mn were obtained by ultrasonic spray pyrolysis and had dimensions of $\mathrm{d} \sim 36$ nm. The changes of photoluminescence end EPR spectra of these nanocrystals in dependence of Mn admixture concentration ( $2-8$ at. $\%$ ) and also at heat treatment in air during 1 hour at $\mathrm{T}=850^{\circ} \mathrm{C}$ were investigated. It is shown that under short-term (7-10 s) nonequilibrium conditions of $\mathrm{ZnO}$ : Mn nanocrystals forming, they consist of a nuclens and shell surface, in which, predominantly, the Mn admixture is concentrated. After annealing, the Mn admixture diffuses into the nucleus of a nanocrystal.
\end{abstract} treatment.

Keywords: photoluminescence spectra, EPR spectra, $\mathrm{ZnO}: \mathrm{Mn}$ nanocrystals, ultrasonic spray pyrolysis, heat

Received 30.09.2018; Received in revised form 28.10.2018; Accepted 21.11.2018

\section{Introduction}

In recent times, the diluted magnetic semiconductors (DMS) attract an attention of researchers because these materials have unique electrical, piezoelectric, optical, and magnetic properties. They can be used in microelectronics for creating multifunctional devices and in spin electronics [1,2]. The operation of such devices is based on the use not only of electric potential in the logic elements but also the electron-spin orientation. They have high storage density and high processing speed. To obtain the DMS materials, it is necessary to dope a nonmagnetic semiconductor with a small amount of admixture of transition metals that leads to the occurrence of ferromagnetic properties (FP) in this semiconductor at room temperature. For the first time, these properties were theoretically foreseen in 2000 [3] for zinc oxide doped with manganese. Further intensive experimental researches confirmed the presence of FP in this compound [4], but in some cases, the obtained results led to the contradictory results $[5,6]$. We also synthesized the nanocrystals (NC) of $\mathrm{ZnO}: \mathrm{Mn}$ that had FP at room temperature. They were synthesized by ultrasonic spray pyrolysis [7]. These FP were largely dependent on the technological conditions of synthesis and disappeared after air annealing of the samples at $\mathrm{T} \geq 800^{\circ} \mathrm{C}$.

Recent studies have shown the important role of a crystalline lattice in the occurrence of FP in DMS defects. Thus, in the paper [8], it was shown that the FP in NC of $\mathrm{ZnO}: \mathrm{Mn}$ are due to the exchange interaction between the $\mathrm{Mn}$ ions indirectly due to the own defects of the crystalline lattice. It was assumed that for the occurrence of magnetic ordering it is necessary to reach the corresponding structure of defects in $\mathrm{NC}[9,10]$. A bright example of the role of defects in the crystalline lattice in the occurrence of FP in the DMS was given by the results of the study [11] that showed that mechanical grinding of $\mathrm{ZnO}: \mathrm{Mn}$ samples in an inert atmosphere could transfer them into a ferromagnetic state. After such grinding, the microcrystals are converted into $\mathrm{NC}$ with the formation of a defective near-surface layer with a large number of oxygen vacancies $\left(\mathrm{V}_{\mathrm{o}}\right)$ [12]. This creates conditions for the interaction of $\mathrm{Mn}$ ions with each other, using $\mathrm{V}_{\mathrm{o}}$ as an intermediary, resulting in the occurrence of the ferromagnetic alignment in $\mathrm{ZnO}: \mathrm{Mn}$ samples at room temperature. Thus, the study of the influence of the own defects of a crystalline lattice on the physical properties of $\mathrm{ZnO}: \mathrm{Mn} \mathrm{NC}$ is a crucial task.

\section{Results and discussion}

The ultrasonic spray pyrolysis is based on the thermal decomposition of aerosol droplets of the precursor solution during their passage through the high-temperature zone of the 
furnace [13]. In this case, the thermal decomposition occurs in the atmosphere of the carrier gas and the final product is plated out on a filter that heated to a certain temperature. This method has the possibility to control such parameters of the final product as the size of the $\mathrm{NC}$, the defects of their surface. It also allows doping the $\mathrm{NC}$ with various doping materials. The key feature of the NC synthesis by ultrasonic spray pyrolysis is that their formation takes place in the volume of microdrops under very non-equilibrium conditions that lead to the occurrence of a large number of defects in the NC.

The purpose of this work was to study the impact of manganese concentration on the formation and structure of own defects, photoluminescence spectrum (PL) and EPR in NC of $\mathrm{ZnO}: \mathrm{Mn}$. To do this, we synthesized $\mathrm{NC}$ samples of $\mathrm{ZnO}: \mathrm{Mn}$ with a concentration of manganese 0, 2, 4 and 8 at. \% according to the method described in the paper [14]. The NC size according to the XRD analysis was $\mathrm{d} \sim 36 \mathrm{~nm}$. The samples were also annealed in air at $\mathrm{T}=850^{\circ} \mathrm{C}$ within 1 hour. The analysis of the PL spectrum of the samples was carried out at the unit that operated in photon counting mode. An ultraviolet light-emitting diode $\left(\lambda_{\max }=\right.$ $375 \mathrm{~nm}$ ) was used as the source of the excitation light. The PL spectra of NC samples of $\mathrm{ZnO}: \mathrm{Mn}$ at $\mathrm{T}=300 \mathrm{~K}$ with different concentrations of $\mathrm{Mn}$ are shown in Fig. 1a. The PL spectra of all samples are located in a green spectral band. It is characteristic that the peaks of the PL spectra are within the limits of $\lambda_{\max }=555.0 \pm 5 \mathrm{~nm}$.
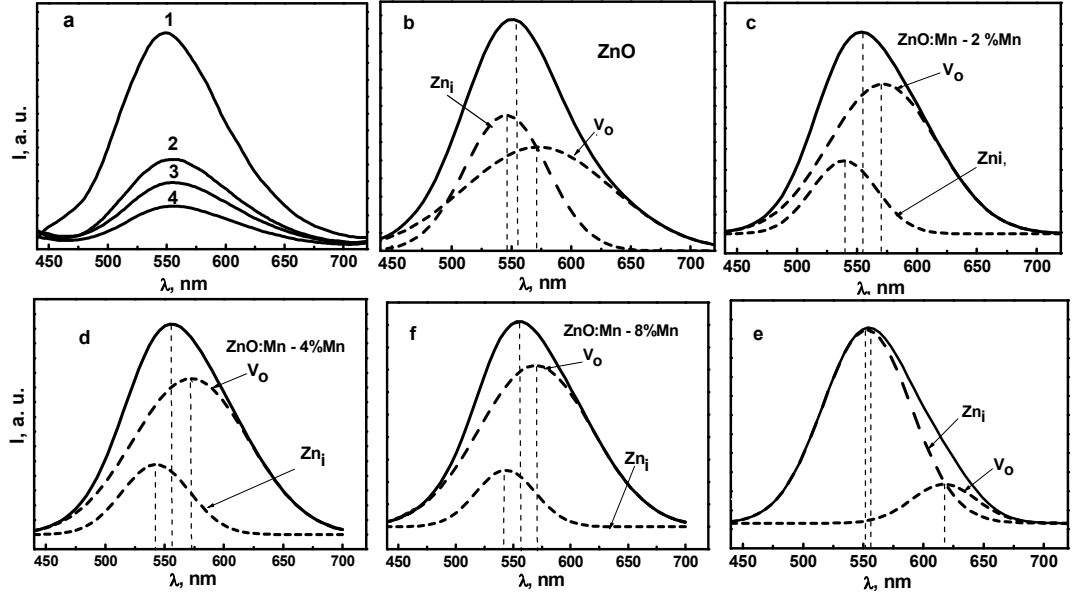

Fig. 1. PL spectra of samples before annealing (a): $\mathrm{NC} \mathrm{of} \mathrm{ZnO}$ - (1), NC of $\mathrm{ZnO}$ :Mn with the concentration of manganese (Mn) in 2 at. \% - (2), 4 at. \% - (3), 8 at. \% - (4), respectively. PL spectrum decompositions for these samples on simple bands - b, c, $d$, f before annealing, $\mathrm{e}$ - typical PL spectra after annealing for all samples at $T=850^{\circ} \mathrm{C}$ within 1 hour, $\mathrm{Zn}_{\mathrm{i}}-$ interstitial zinc, $\mathrm{V}_{\mathrm{o}}$ - oxygen vacancies.

The spectrum analysis shows that the increase in the concentration of the doping $\mathrm{Mn}$ leads to the decrease in the PL emission intensity (Fig. 1a). This can be explained by the fact that manganese at the doping of $\mathrm{ZnO} \mathrm{NC}$ increases the concentration of radiation-free centers. It is believed that green PL arises as a result of the recombination of free electrons and holes in the centers of interstitial zinc $\left(\mathrm{Zn}_{\mathrm{i}}\right)$ and oxygen vacancies $\left(\mathrm{V}_{\mathrm{o}}\right)$ [15]. Considering this, the decomposition of the PL spectrum of obtained samples into simple bands was carried out using known data that the dominating bands in the ZnO PL spectrum were $\lambda_{1}=539 \mathrm{~nm}$ and $\lambda_{2}=582 \mathrm{~nm}$ that related to interstitial zinc $\left(\mathrm{Zn}_{\mathrm{i}}\right)$ and oxygen vacancies $\left(\mathrm{V}_{\mathrm{o}}\right)$ in accordance with Fig. 1b - 1e [16]. The peaks of these bands are somewhat shifted from the above mentioned values, perhaps because they, in their turn, are not simple and due to the presence of additional PL centers in $\mathrm{ZnO}: \mathrm{Mn}$. Comparison of the PL spectrum of pure $\mathrm{ZnO}$ and the doped samples with the concentration of doping $\mathrm{Mn}$ in $2-8$ at. \% shows that the number of 
oxygen vacancies $\mathrm{V}_{\mathrm{o}}$ increases in samples at doping and amount of $\mathrm{Zn}_{\mathrm{i}}$ decreases. The increase of the concentration of doping $\mathrm{Mn}$ from 4 at. \% does not lead to a significant increase in the number of oxygen vacancies $V_{o}$ (Fig. 1d - 1f). This is explained by the fact that the solubility limit of the admixture Mn under such non-equilibrium synthesis conditions does not exceed 4 at.\% [7]. At concentrations of the admixture, that exceed the solubility limit, the residual $\mathrm{Mn}$ is no longer included in the crystalline lattice of $\mathrm{ZnO}$, but is accumulated on the surface of the NC and causes the formation of admixture phases. This is confirmed by the data of XRD analysis [7]. After annealing in air $\left(\mathrm{T}=850^{\circ} \mathrm{C}\right)$ within 1 hour this manganese diffuses from the surface into a crystalline lattice of $\mathrm{ZnO}$ replacing $\mathrm{Zn}$ atoms. This reduces the number of oxygen vacancies $\mathrm{V}_{\mathrm{o}}$ that leads to a decrease in the intensity of the corresponding band and increases the number of vacancies of interstitial zinc $\mathrm{Zn}_{\mathrm{i}}$ (Fig. 1e). After annealing, the PL spectrum of all samples become similar and independent of the concentration of the Mn admixture. The EPR spectrum of the obtained samples (Fig. 2) were analyzed on the radiospectrometer RADIOPAN SE/X 2543.
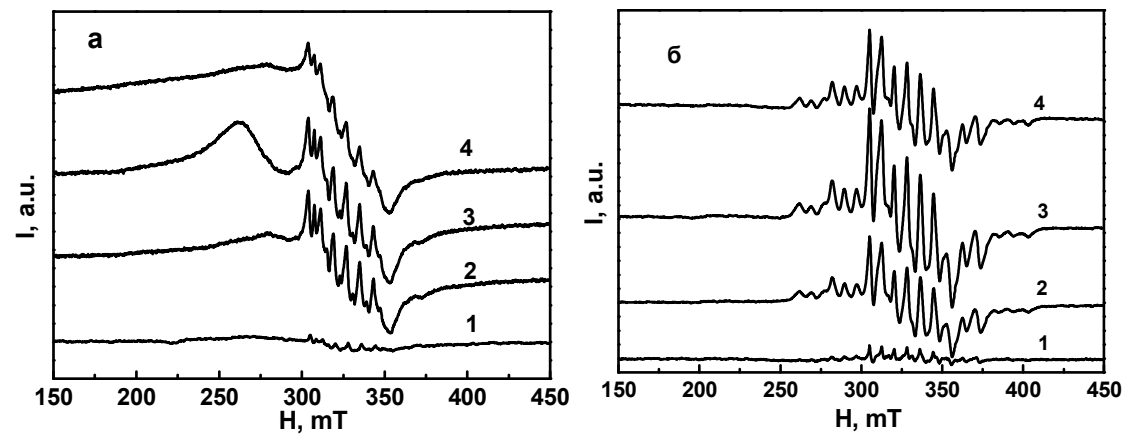

Fig. 2. EPR spectra of $\mathrm{ZnO}$ nanocrystals - (1) and $\mathrm{ZnO}$ :Mn nanocrystal samples with doping concentration of manganese (Mn) 2 at. \% - (2), 4 at. \% - (3), 8 at. \% - (4), accordingly, before (a) and after (b) annealing.

By analyzing the EPR spectrum of synthesized samples before annealing, the inference should be drawn that absorption lines are almost not registered in pure $\mathrm{ZnO}$. The EPR spectra of $\mathrm{ZnO}: \mathrm{Mn} \mathrm{NC}$ with admixture Mn concentrations of 2, 4, and 8 at. \% consist of a broad background absorption line due to the dipole-dipole interaction of manganese ions and six lines of hyperfine structure (HFS) of $\mathrm{Mn}^{2+}$ ions that are isovalently substituted by $\mathrm{Zn}^{2+}$ ions in a crystalline lattice of $\mathrm{ZnO}$. The doping of $\mathrm{ZnO}$ with the $\mathrm{Mn}$ admixture results in an increase in the intensity of the background line, a decrease in the amplitudes of the HFS lines due to the increase in the dipole-dipole interaction. In this case, the background absorption line becomes dominant. This is especially true for the EPR spectra of ZnO:Mn NC with an admixture concentration in 8 at.\%. This may indicate a partial doping process, i.e. that the manganese ions, despite the increase in the concentration of the admixture, do not replace all zinc ions in the crystalline lattice of $\mathrm{ZnO}$. They are located in a large amount on the surface of the NC, forming a defective shell of $\mathrm{NC}$ and in an intercrystal environment. Thus, the type of the EPR spectrum of samples before annealing gives grounds to assume that there is a defective surface layer in the $\mathrm{NC}$ of $\mathrm{ZnO}: \mathrm{Mn}$. The type of EPR spectrum changes after annealing of the samples at temperature $\mathrm{T}=850^{\circ} \mathrm{C}$ is shown in Fig. 2b. It consists of intensive lines of HFS of both central and lateral transitions. The wide background absorption line has practically disappeared. This may indicate that due to thermal diffusion almost all manganese ions are located in a crystalline lattice of $\mathrm{ZnO}$. Thus, the EPR spectrum of samples after annealing confirms the fact of the volume doping of $\mathrm{ZnO} \mathrm{NC}$ by a manganese admixture and the disappearance of the defective surface layer. The comparison of the EPR spectrum of $\mathrm{ZnO}: \mathrm{Mn} \mathrm{NC}$ with the concentration of the admixture Mn of 2 at.\% (Fig. 3) is an 
additional proof of the existence of an inhomogeneous crystalline structure of $\mathrm{ZnO}: \mathrm{Mn} \mathrm{NC}$ in the form of a defect-free nucleus and a defective shell. That is why until the annealing in such samples the HFS lines of the $\mathrm{Mn}^{2+}$ ions are double. This spectrum consists of a superposition of two spectra (SI and SII) and indicates that the $\mathrm{Mn}^{2+}$ ions are in different local environments.

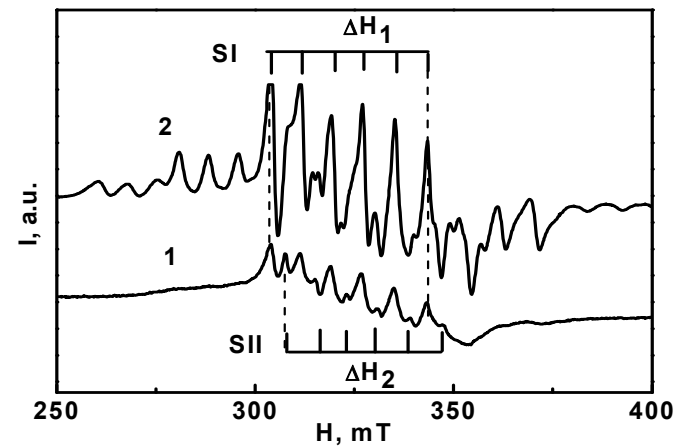

Fig. 3. EPR spectra of $\mathrm{ZnO}$ :Mn nanocrystals with the manganese (Mn) concentration of 2 at. \% before (1) and after (2) annealing.

The shift between the spectrum is $\Delta \mathrm{H}=3.9 \mathrm{mT}$. The SI spectrum is due to the $\mathrm{Mn}^{2+}$ ions that are isovalently substituted by $\mathrm{Zn}^{2+}$ ions in the nodes of the crystalline lattice of $\mathrm{ZnO} \mathrm{NC}$. The SII spectrum is associated with $\mathrm{Mn}^{2+}$ ions that are located in a deformed near-surface layer. The width of the SI spectrum is $\Delta \mathrm{H}_{1}=39.52 \mathrm{mT}$, the constant of the superfine interaction $\mathrm{A}=7.9 \mathrm{mT}$. The width of the SII spectrum is $\Delta \mathrm{H}_{2}=41.65 \mathrm{mT}$, the constant $\mathrm{A}=$ $8.3 \mathrm{mT}$. After annealing, the intensity of the HFS lines of the EPR spectrum is redistributed in favor of the SI spectrum. The SII spectrum is not detected that is an illustration of the diffusion of $\mathrm{Mn}^{2+}$ ions from the near-surface layer in the volume of $\mathrm{ZnO} \mathrm{NC}$ and the disappearance of the defective shell.

\section{Conclusions}

Our study shows that annealing of the NBT thin films at $700^{\circ} \mathrm{C}$ shows lower levels of leakage currents in comparison with the levels in the films annealed at $800^{\circ} \mathrm{C}$. Realization of two conduction mechanisms in films annealed at $700^{\circ} \mathrm{C}$ can be assumed: ohmic $(\mathrm{E}<8 \mathrm{kV} / \mathrm{cm})$ and Schottky emission (field range of $30-70 \mathrm{kV} / \mathrm{cm}$ ). High values of leakage currents can be caused by the presence of an additional phase and structural defects in the films, in particular, $V_{O^{2-}}{ }^{-*}$ vacancies. The increase in the annealing temperature of NBT films does not lead to the decrease of the $V_{O^{2-*}}$ vacancies number and, as a result, does not lead to $\mathrm{J}$ decrease.

\section{References}

1. Priya, S. Lead-Free Piezoelectrics / S.Priya, S. Nahm eds. - New York: Springer, 2012. -537 p.

2. Daryapurkar A.S. Influence of oxygen gas pressure on phase, microstructure and electrical properties bismuth titanate thin films grown using pulsed laser deposition / A.S. Daryapurkar, J.T. Kolte, P. Gopolan // Thin Solid Films. - 2015. - Vol. 579.- P. 44 - 49.

3. Kamenshchikov M.V. Conductivity and current-voltage characteristics of thin-film heterostructures based on PZT / M.V. Kamenshchikov, A.V. Solnyshkin, A.A. Bogomolov, I.P. Pronin // Solid State Physics.- 2011.- Vol. 53, No. 10. - P.1975 - 1979

4. Diao, C.C. Effects of rapid thermal annealing treatment on $0.95\left(\mathrm{Na}_{0.5} \mathrm{Bi}_{0.5}\right) \mathrm{TiO}_{3}-0.05 \mathrm{BaTiO}_{3}$ thin films / C.C. Diao, C.F. Yang // Advances in Applied Ceramics. - 2010. - Vol. 109, No. 7. - P. 421 - 425.

5. Kruzina, T.V. Impedance spectra of as-grown and heat treated $\mathrm{Na}_{0.5} \mathrm{Bi}_{0.5} \mathrm{TiO}_{3}$ crystals / T.V. Kruzina, V.M. Sidak, M.P. Trubitsyn, S.A. Popov, A.Yu. Tuluk and J. Suchanicz // Acta Physica Polonica. - 2018. - Vol. 133, No. 4. - P. 816-818. 